\title{
Adherence to inhaled therapy and its impact on chronic obstructive pulmonary disease (COPD)
}

\author{
Magdalena Humenberger ${ }^{1,2}$, Andreas Horner ${ }^{1,2^{*}} \mathbb{D}$, Anna Labek $^{3}$, Bernhard Kaiser ${ }^{3}$, Rupert Frechinger ${ }^{4}$, \\ Constanze Brock ${ }^{1}$, Petra Lichtenberger ${ }^{1}$ and Bernd Lamprecht ${ }^{1,2}$
}

\begin{abstract}
Background: COPD is a treatable disease with increasing prevalence worldwide. Treatment aims to stop disease progression, to improve quality of life, and to reduce exacerbations. We aimed to evaluate the association of the stage of COPD on adherence to inhaled therapy and the relationship between adherence and COPD exacerbations.

Methods: A retrospective analysis of patients hospitalized for acute exacerbation of COPD in a tertiary care hospital in Upper Austria and discharged with a guideline conform inhaled therapy was performed. Follow-up data on medical utilization was recorded for the subsequent 24 months. Adherence to inhaled therapy was defined according to the percentage of prescribed inhalers dispensed to the patient and classified as complete $(>80 \%)$, partial $(50-80 \%)$ or low $(<50 \%)$.
\end{abstract}

Results: Out of 357 patients, $65.8 \%$ were male with a mean age of 66.5 years and a mean $\mathrm{FEV}_{1}$ of $55.0 \%$ pred. Overall, $35.3 \%$ were current smokers, and only $3.9 \%$ were never-smokers. In $77.0 \%$ inhaled triple therapy (LAMA + LABA + ICS) was prescribed. 33.6\% showed complete adherence to their therapy (33.2\% in men, 34.4\% in women), with a mean age of 67.0 years. Mean medication possession ratio by GOLD spirometry class I - IV were $0.486,0.534,0.609$ and 0.755 , respectively $(p=0.002)$. Hence, subjects with complete adherence to therapy had a significantly lower $\mathrm{FEV}_{1}$ compared to those with low adherence (49.2\%pred. vs 59.2\%pred., respectively; $p<0.001$ ).

The risk of exacerbations leading to hospitalization was 10-fold higher in GOLD spirometry class IV compared to GOLD spirometry class I, which was even more evident in multivariate analysis (OR 13.62).

Conclusion: Complete adherence to inhaled therapy was only seen in $33.6 \%$ and was higher among those with more severe COPD.

Trial registration: Not applicable.

Keywords: Chronic obstructive pulmonary disease, Adherence, Inhaled therapy

\section{Background}

Chronic obstructive pulmonary disease (COPD) is an underdiagnosed, preventable and treatable disease with increasing prevalence worldwide. It has been a major problem over decades and will be a challenge within the twenty-first century [1-4].

\footnotetext{
* Correspondence: Andreas.Horner@kepleruniklinikum.at

${ }^{1}$ Department of Pulmonology, Kepler University Hospital, Krankenhausstrasse 9. A4021, Linz, Austria

${ }^{2}$ Faculty of Medicine, Johannes-Kepler-University, Linz, Austria

Full list of author information is available at the end of the article
}

To reduce mortality in COPD patients, lower the economic and clinical burden and to improve quality of life, it is crucial to prevent disease progression, reduce exacerbation rates and focus on the treatment of comorbidities [59]. Adherence to inhaled therapy appears to have significant impact on treatment goals. Therefore, it is crucial to increase the patients' and physicians' awareness concerning this topic.

Only few data are available on adherence and influencing factors. A meta-analysis of over 50 years of research on adherence shows an association between adherence and social and emotional resources [10, 11]. In a study

(c) The Author(s). 2018 Open Access This article is distributed under the terms of the Creative Commons Attribution 4.0 International License (http://creativecommons.org/licenses/by/4.0/), which permits unrestricted use, distribution, and 
of patients including those with COPD by Balkrishnan et al., the numbers of hospitalization rates and physician visits were reduced in patients who were adherent to prescribed therapy [12].

Nonadherence is a tremendous problem in the treatment of patients in general [13]. Furthermore, adherence in COPD patients is particularly poor and reported nonadherence rates range from 50 to $80 \%$ [14-16].

In patients with COPD, nonadherence to inhaled therapy is caused by several factors and could lead to high mortality and morbidity as well as hospitalizations and a reduced quality of life [14, 17-21]. Thus, the consequences of nonadherence, clinically and economically, are neither completely obvious nor fully understood, but there is an association between nonadherence and increasing healthcare costs [17, 19, 22, 23].

The aim of this retrospective data analysis was to evaluate the association of the stage of COPD on adherence and the relationship between adherence and COPD exacerbations. We hypothesized, that better adherence is associated with less COPD exacerbations leading to hospitalization.

\section{Methods}

The primary outcome parameter of this retrospective analysis was to describe the characteristics of an Upper Austrian COPD cohort based upon degree of adherence to inhaled therapy and its association with spirometrically defined COPD stages. Moreover, we explored adherence as a risk factor for the poor outcome of exacerbation risk and we described further influencing factors on adherence.

Data of patients hospitalized for COPD exacerbations at the department for pulmonology in a tertiary care hospital in Upper Austria and discharged with a guideline conform inhaled therapy in 2012 were analyzed. The following observation period was 24 months. Patients who died within the first six months of the observation period were excluded due to the short observation period. However, patients who died afterwards but during the observation period, were included until death. Hence, the observation period was shorter in these patients and it was assumed that these individuals would have continued with the same adherence routine prior to their death.

Inclusion criteria were age $>40$ years, COPD diagnosis (GOLD spirometry class I - IV) based on lung function testing (post-bronchodilator $\mathrm{FEV}_{1} / \mathrm{FVC}<70 \%$ ) and a prescribed permanent inhaled therapy. Inhaled therapy was prescribed according to the risk assessment $(A-D)$ as proposed in the GOLD report 2011 [24].

All patients discharged in 2012 were screened looking for a diagnosis with ICD-10-Code 44.0-44.9 at time of discharge. COPD diagnosis and stage were verified by the most recent lung function performed in 2012. Based on lung function criteria, patients with partial post-bronchodilator reversibility were included. However, patients with complete reversibility $\left(\Delta \mathrm{FEV}_{1}>12 \%\right.$, or $>0.2$ l) were excluded.

Adherence to inhaled therapy, based on the 24 months observation period, was defined according to the percentage of prescribed inhalers dispensed to the patient and classified as follows: Complete adherence $(>80 \%)$, partial adherence $(50-80 \%)$ and low adherence $(<50 \%)$. $80 \%$ is a frequently used threshold for the differentiation of adherence (high or low) [23]. We decided to further divide the participants according to adherence into three groups to show more precise results in the low adherence group (partial and low adherence).

Additionally, adherence was reported as mean medication possession ratio (MPR) [25], and categorized by sex, $\mathrm{FEV}_{1}$ \%pred, smoking status and inhaled therapy. The MPR was calculated using the ratio of personal adherence months to the whole observation period of each participant.

For a permanent inhaled therapy, one medical prescription per month for each device was assumed for complete adherence. Complete data therefore was provided by the Upper Austrian Health Insurance (OÖGKK).

Statistical analysis was performed using SAS 9.3. Figures and tables were created with Microsoft Excel 2016. The adherence category (complete, partial, low) was the underlying and central variable in all statistical analyses performed in this study. The association between adherence and most important covariates (age, sex, $\mathrm{FEV}_{1} \%$ pred, smoking status) is shown in a descriptive overview using means and proportions.

Nonparametric Chi-square test, Mann-Whitney U test and $t$-test were used to investigate differences between groups according to adherence category.

COPD control was assessed using the rate of severe exacerbations leading to hospitalization per year. Concerning exacerbations leading to hospitalization a binary univariate and multivariate logistic regression analysis was performed, based on odds ratios, to determine the influence of several factors (age, sex, $\mathrm{FEV}_{1}$ \%pred, smoking status, adherence) on exacerbation rates.

Results are mainly expressed as frequencies or as mean. Statistical significance was defined as $p<0.05$ for all analyses in this study.

\section{Results}

Out of 592 hospitalized patients with COPD and discharged with a guideline conform inhaled therapy in 2012, complete data was available of 476 cases in the database of the Upper Austrian Health Insurance 
(OÖGKK). 54 subjects died within 6 months after discharge and 65 had no prescription for permanent inhaled medication and were therefore excluded (Fig. 1).

Out of 357 patients, $65.8 \%$ were male and $34.2 \%$ were female, with a mean age of 66.5 years and a mean $\mathrm{FEV}_{1}$ of $55.0 \%$ pred. $55 \%$ had GOLD spirometry class I - II COPD and 45\% had GOLD spirometry class III - IV COPD. Overall, 35.3\% were current smokers, $57.4 \%$ former smokers and only $3.9 \%$ were never smokers. In $77.0 \%$ of all cases, inhaled triple therapy (LAMA + LABA + ICS) was prescribed at the time of discharge (for other inhaled therapies see Table 1). $74.2 \%$ had an additional prescription for SAMA and/or SABA, as inhaled therapy on demand. $17 \%$ of all subjects were on long-term oxygen therapy. There was no significant difference between men and women concerning age, $\mathrm{FEV}_{1}$, smoking status or long-term oxygen therapy. However, significantly more male patients were treated with triple therapy (83.0\% vs $65.6 \% ; p<0.001)$.
$33.6 \%$ of 357 patients showed complete adherence to their therapy (33.2\% in men, $34.4 \%$ in women), with a mean age of 67.0 years and a mean $\mathrm{FEV}_{1}$ of $49.2 \%$ predSubjects with complete adherence to therapy had a significantly lower $\mathrm{FEV}_{1}$ compared to those with low adherence (49.2\%pred. vs 59.2\% pred., respectively; $\mathrm{p}<0.001$ ). (for further baseline characteristics by adherence see Table 2).

Among all 357 patients, complete adherence was noted in $44.9 \%$ of GOLD spirometry category IV participants, while only $19.4 \%$ of GOLD spirometry category I were noted to be completely adherent (Fig. 2).

Using the medication possession ratio (MPR), to describe adherence, the overall mean MPR was 0.565. Hence, on average patients were adherent in $56.5 \%$ of all months during the observation period.

Male patient had slightly higher MPRs than females ( 0.568 vs 0.558 , respectively; $p=0.883$ ). MPRs by GOLD spirometry class I - IV were $0.486,0.534,0.609$ and 0.755 , respectively. These differences were statistically highly significant $(p=0.002)$. Former smokers had a higher mean

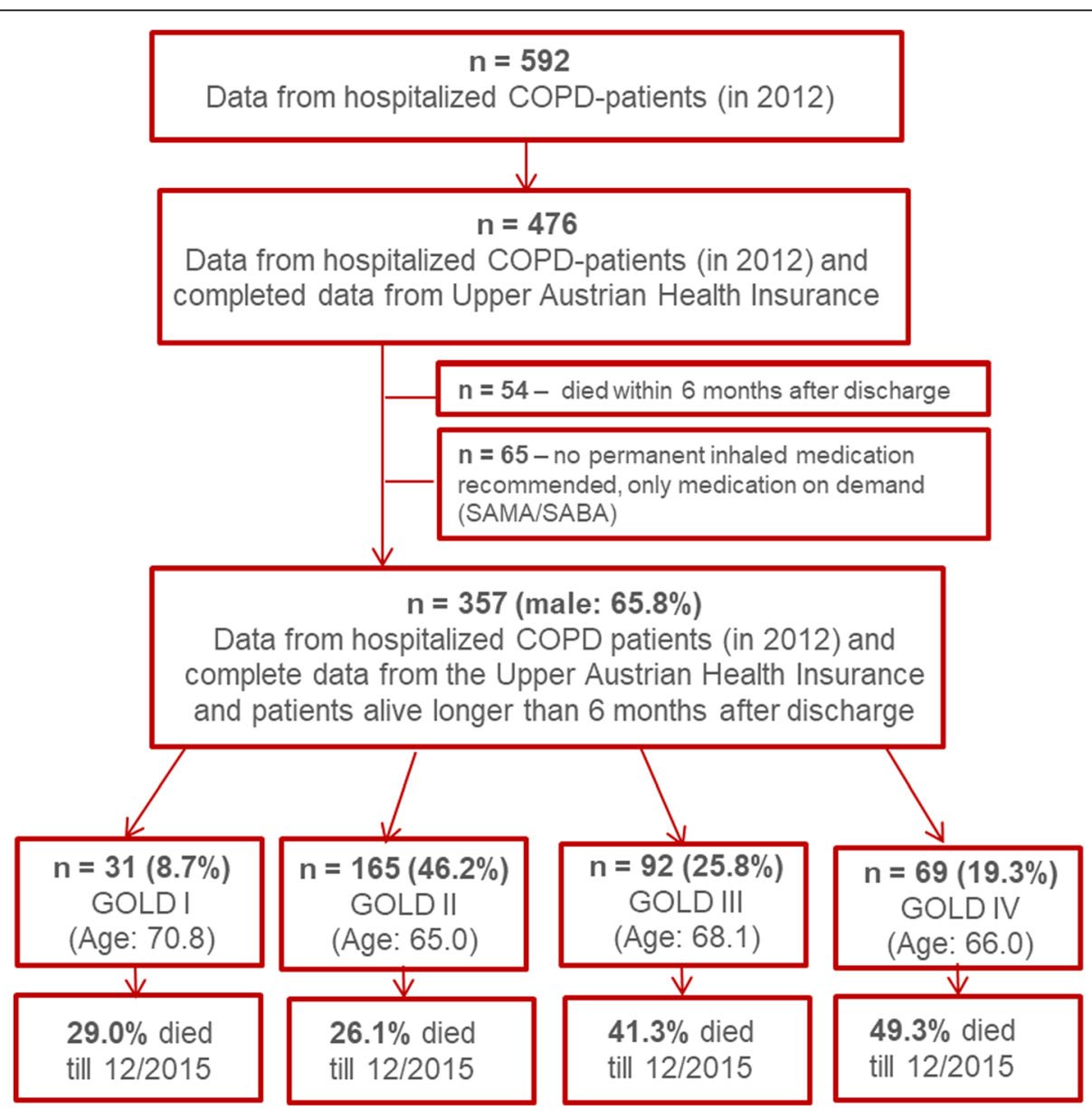

Fig. 1 Study population 
Table 1 Characteristics of the participants at baseline

\begin{tabular}{lllll}
\hline & All & Female & Male & $p$-value \\
\hline n (\%) & 357 & $122(34.2)$ & $235(65.8)$ & \\
Age in year, mean (SD) & $66.5(10.6)$ & $66.1(11.1)$ & $66.7(10.0)$ & 0.580 \\
FEV $\%$ pred., mean (SD) & $55.0(18.5)$ & $58.0(19.4)$ & $53.4(17.9)$ & 0.067 \\
Smoking status, n (\%) & & & & \\
$\quad$ Current smoker & $126(35.3)$ & $43(35.3)$ & $83(35.3)$ & 0.982 \\
Former smoker & $205(57.4)$ & $67(54.9)$ & $138(58.7)$ & 0.471 \\
Never smoker & $14(3.9)$ & $8(6.5)$ & $6(2.6)$ & 0.065 \\
No information & $12(3.4)$ & $4(3.3)$ & $8(3.4)$ & \\
Inhaled Therapy, n (\%) & & & & \\
LAMA only & $10(2.8)$ & $3(2.5)$ & $7(3.0)$ & 0.777 \\
LABA only & $3(0.8)$ & $2(1.6)$ & $1(0.4)$ & 0.233 \\
LABA + ICS & $64(17.9)$ & $34(27.9)$ & $30(12.8)$ & $<0.001$ \\
LAMA + LABA + ICS & $275(77.0)$ & $80(65.6)$ & $195(83.0)$ & $<0.001$ \\
LABA + LAMA & $5(1.4)$ & $3(2.5)$ & $2(0.9)$ & 0.952 \\
LTOT, n (\%) & $60(17.0)$ & $26(21.5)$ & $34(14.7)$ & 0.101 \\
\hline
\end{tabular}

LAMA - long-acting muscarinic antagonist; LABA - long-acting betaadrenoceptor agonist; ICS - inhaled corticosteroid; LTOT - long-term oxygen therapy

MPR (0.610) compared to smokers (0.510) and never smokers $(0.464)(p=0.021)$. Patients on triple therapy (LABA + LAMA + ICS) were, statistically not significant, more adherent compared to patients on other therapy regimes (0.584 vs 0.499 , respectively; $p=0.089$ ).

Table 3 shows the results of a binary univariate and multivariate logistic regression analysis of factors independently associated with exacerbations leading to hospitalizations during the observation period. The risk of exacerbations leading to hospitalization was 10-fold higher in GOLD stage IV compared to GOLD stage I (OR 10.69; CI 2.99; 38.24) in univariate analysis. In the univariate and multivariate analysis, an inverse association between adherence to therapy and exacerbations leading to hospitalization was observed. Subjects with

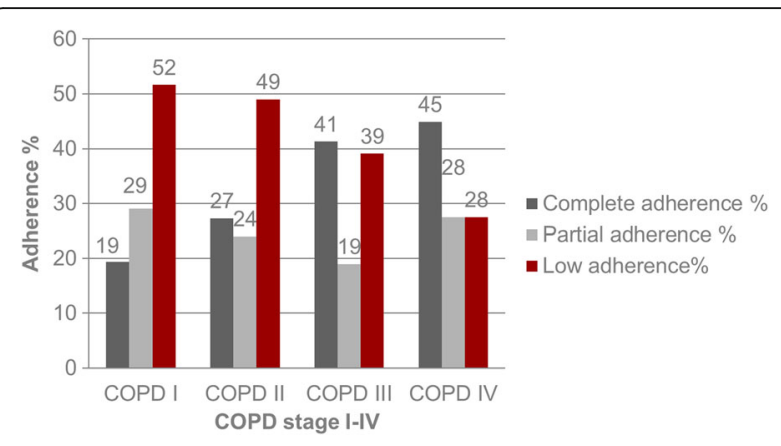

Fig. 2 Adherence by stage of COPD, $n=357$

low adherence had a reduced risk of exacerbations (not significant in multivariate analysis; OR $0.58 ; 95 \% \mathrm{CI}$ (0.33; 1.02)); for details see Table 3 ).

\section{Discussion}

In our retrospective data analysis, we were able to show that adherence to inhaled therapy in COPD patients is generally low. Complete adherence to inhaled therapy was only seen in $33.6 \%$. Factors associated with better adherence were age, former smoking, and more severe airflow limitation.

In prior studies adherence in COPD ranged between 70 to $90 \%$ in several clinical trials; however, in clinical practice, adherence is lower within the range of $10-40 \%$, irrespective of the probable insufficient or incorrect use of the device [15, 26, 27].

We could show that adherence to inhaled therapy was higher in GOLD spirometry class III - IV COPD and was highest in patients with GOLD spirometry class IV COPD. This may be due to the fact, that with advanced disease and a higher burden of symptoms, the inhaled medication is perceived more necessary by the patient. The association between symptom relief and medication use may be a potent trigger for better adherence [16]. Contrariwise, lack of clinical symptoms can be

Table 2 Baseline characteristics of patients by adherence; $n=357$

\begin{tabular}{|c|c|c|c|c|c|}
\hline & Complete adherence (> 80\%) & Partial adherence (50-80\%) & Low adherence $(<50 \%)$ & All & $p$-value \\
\hline n (\%) & $120(33.6)$ & $85(23.8)$ & $152(42.6)$ & 357 & \\
\hline Sex, n (\%) & & & & & 0.865 \\
\hline Female $(\%, n=122)$ & $42(34.4)$ & $27(22.1)$ & $53(43.5)$ & 122 & \\
\hline Male $(\%, n=235)$ & $78(33.2)$ & $58(24.7)$ & $99(42.1)$ & 235 & \\
\hline Age in years, mean (SD) & $67.0(9.2)$ & $66.7(9.9)$ & $66.0(11.5)$ & $66.5(10.4)$ & 0.920 \\
\hline FEV $1 \%$ pred, mean (SD) & $49.2(17.6)$ & $56.0(18.3)$ & $59.2(18.2)$ & $55.0(18.5)$ & $<0.001$ \\
\hline Smoking status, n (\%) & & & & & 0.081 \\
\hline Current smoker & $33(27.5)$ & $31(36.5)$ & $62(40.8)$ & $126(35.3)$ & \\
\hline Former smoker & $81(67.5)$ & $48(56.5)$ & $76(50.0)$ & $205(57.4)$ & \\
\hline Never smoker & $3(2.5)$ & $3(3.5)$ & $8(5.3)$ & $14(3.9)$ & \\
\hline No information & $3(2.5)$ & $3(3.5)$ & $6(3.9)$ & $12(3.4)$ & \\
\hline
\end{tabular}


Table 3 Parameters independently associated with severe exacerbations/ hospitalizations; $\mathrm{n}=357$

\begin{tabular}{lll}
\hline & OR $(95 \% \mathrm{Cl})$ crude & OR $(95 \% \mathrm{Cl})$ adjusted \\
\hline $\begin{array}{l}\text { Gender } \\
\text { Female }\end{array}$ & Reference & Reference \\
$\begin{array}{l}\text { Male } \\
\text { Age (years })\end{array}$ & $0.89(0.58 ; 1.38)$ & $0.95(0.57 ; 1.57)$ \\
$<50$ & & \\
$50-60$ & Reference & Reference \\
$60-70$ & $1.68(0.56 ; 5.06)$ & $0.87(0.26 ; 2.90)$ \\
$>70$ & $2.12(0.74 ; 6.07)$ & $1.00(0.32 ; 3.13)$ \\
FEV ${ }_{1}$ & $1.12(0.39 ; 3.21)$ & $0.71(0.22 ; 2.24)$ \\
$>80 \%$ pred. & & \\
$50-80 \%$ pred. & Reference & Reference \\
30-50\% pred. & $0.86(0.39 ; 1.88)$ & $0.94(0.40 ; 2.24)$ \\
$<30 \%$ pred. & $10.69(2.99 ; 38.24)$ & $13.62(3.11 ; 59.63)$ \\
Smoking status & & \\
Current smoker & Reference & Reference \\
Former smoker & $1.11(0.71 ; 1.73)$ & $1.19(0.70 ; 2.02)$ \\
Never smoker & $0.67(0.21 ; 2.12)$ & $0.82(0.23 ; 2.92)$ \\
Adherence to therapy & & \\
Complete $(\geq 80 \%)$ & Reference & Reference \\
Partial $(50-80 \%)$ & $0.77(0.44 ; 1.35)$ & $0.95(0.50 ; 1.78)$ \\
Low $(<50 \%)$ & $0.44(0.27 ; 0.71)$ & $0.58(0.33 ; 1.02)$ \\
\hline
\end{tabular}

misinterpreted and can lead to treatment interruption and cessation [26]. This is in accordance with previous studies, where adherence was better in patients with more severe disease [28, 29].

In our univariate and multivariate analysis, the risk of exacerbations leading to hospitalization was more than 10-fold higher in GOLD stage IV compared to GOLD stage I. Patients with low adherence tended to have a reduced risk for exacerbations leading to hospitalization (OR 0.58; $0.33,1.02$; not significant in multivariate analysis).

In previous research, better adherence in COPD patients was associated with a reduced risk for exacerbations and health care utilization $[18,30]$.

This paradoxical result may be caused by other influencing factors as this trend was considerably less pronounced and statistically not significant in multivariate compared to univariate analysis. Furthermore, the nonadherent patients predominately had GOLD spirometry class I - II COPD with less impairment of lung function, probably less symptoms and better quality of life.

Adherence in COPD patients is complex and multiple factors may be influencing. Parameters associated with poor adherence include the dosing regime, drug side effects, comorbidities, age and costs, the patient's disease perception but also social factors $[14,15,23]$.
Possibilities to improve adherence include knowledge about self-management, overcoming misperceptions, close communication and shared decision-making between patients and their physicians, simple therapy regimes and low out-of-pocket costs for medications [13, 18, 23, 26, 31-33].

\section{Limitations}

Due to administrative limitations, we could only include patients insured by the Upper Austrian Health Insurance (OÖGKK). Therefore, we have no data for subjects insured by other health insurance companies. However, the Upper Austrian Health Insurance covers more than $80 \%$ of the general Upper Austrian population.

As a noninterventional study, we were not able to use electronically monitored inhalers, adherence scores or questionnaires to evaluate adherence. Although prescription refill rates are widely used in scientific literature, they may not perfectly reflect the electronically monitored inhaler use of COPD patients [34]. Moreover, refill rates might depend on social support and cognitive abilities of COPD patients [35-37]. Unfortunately, there is no data about the social framework of our patients available. As adherence was classified by dispensed inhalers, we are not able to evaluate if the patients have taken their medication correctly.

\section{Conclusion}

Complete adherence to inhaled therapy was only seen in about one third of subjects with a prior hospitalization due to a COPD exacerbation. Adherence was significantly higher among those with spirometrically more severe COPD.

Identifying reasons for and a better understanding of underlying causes of poor adherence are necessary and warrant further research.

\section{Abbreviations}

COPD: chronic obstructive pulmonary disease; $\mathrm{FEV}_{1}$ : forced expiratory volume in $1 \mathrm{~s}$; FVC: forced vital capacity; GOLD: Global Initiative for Chronic Obstructive Lung Disease; ICD-10: 10th revision of the International Statistical Classification of Diseases; ICS: inhaled corticosteroid; LABA: long-acting beta-adrenoceptor agonist; LAMA: long-acting muscarinic antagonist; MPR: medication possession ratio; pred: predicted; SABA: short-acting beta-adrenergic agonist; SAMA: short-acting muscarinic antagonist

\section{Funding}

The Upper Austrian Health Insurance supported the current work with an unrestricted grant. AL and BK are employees of and data on adherence was provided by the Upper Austrian Health Insurance. However, this funding source had no role in study design, data analysis, decision to publish, or preparation of the manuscript.

\section{Availability of data and materials}

The datasets analyzed during the current study are available from the corresponding author on reasonable request.

\section{Authors' contributions}

$\mathrm{MH}, \mathrm{AH}, \mathrm{BK}, \mathrm{AL}$ and $\mathrm{BL}$ contributed to the study conception and design, data analysis and interpretation. $\mathrm{MH}, \mathrm{AH}, \mathrm{PL}$ and $\mathrm{BL}$ contributed to drafting the manuscript. RF, CB contributed to the data acquisition, data interpretation and critical revision of the manuscript for important intellectual content. All authors approved the final manuscript. 


\section{Ethics approval and consent to participate}

The current work was approved by the local ethical review committee ("Ethikkommission des Landes Oberösterreich") under the following reference number: |-16-15.

\section{Consent for publication}

Not applicable.

\section{Competing interests}

The authors declare that they have no competing interests. AL and BK are employees of the Upper Austrian Health Insurance.

\section{Publisher's Note}

Springer Nature remains neutral with regard to jurisdictional claims in published maps and institutional affiliations.

\section{Author details}

${ }^{1}$ Department of Pulmonology, Kepler University Hospital, Krankenhausstrasse 9, A4021, Linz, Austria. 'Faculty of Medicine, Johannes-Kepler-University, Linz, Austria. ${ }^{3}$ Department of Health Economics, Upper Austrian Health Insurance, Linz, Austria. ${ }^{4}$ Department of Medical Controlling, Kepler University Hospital, Linz, Austria.

Received: 16 April 2018 Accepted: 18 September 2018 Published online: 19 October 2018

\section{References}

1. Buist AS, McBurnie MA, Vollmer WM, Gillespie S, Burney P, Mannino DM, Menezes AM, Sullivan SD, Lee TA, Weiss KB, et al. International variation in the prevalence of COPD (the BOLD study): a population-based prevalence study. Lancet. 2007:370(9589):741-50.

2. Firlei N, Lamprecht B, Schirnhofer L, Kaiser B, Studnicka M. The prevalence of COPD in Austria--the expected change over the next decade. Wien Klin Wochenschr. 2007;119(17-18):513-8.

3. Lamprecht B, Soriano JB, Studnicka M, Kaiser B, Vanfleteren LE, Gnatiuc L, Burney P, Miravitlles M, Garcia-Rio F, Akbari K, et al. Determinants of underdiagnosis of COPD in national and international surveys. Chest. 2015:148(4):971-85.

4. Lopez-Campos JL, Tan W, Soriano JB. Global burden of COPD. Respirology. 2016;21(1):14-23.

5. Wouters EF. Economic analysis of the Confronting COPD survey: an overview of results. Respir Med. 2003;97(Suppl C):S3-14

6. Anzueto A, Sethi S, Martinez FJ. Exacerbations of chronic obstructive pulmonary disease. Proc Am Thorac Soc. 2007;4(7):554-64.

7. Foster TS, Miller JD, Marton JP, Caloyeras JP, Russell MW, Menzin J. Assessment of the economic burden of COPD in the U.S.: a review and synthesis of the literature COPD: J Chron Obstruct Pulmon Dis. 2009:3(4):211-8.

8. Beran D, Zar HJ, Perrin C, Menezes AM, Burney P. Forum of international respiratory societies working group c: Burden of asthma and chronic obstructive pulmonary disease and access to essential medicines in lowincome and middle-income countries. Lancet Respir Med. 2015:3(2):159-70.

9. Lisspers K, Larsson K, Johansson G, Janson C, Costa-Scharplatz M, Gruenberger JB, Uhde M, Jorgensen L, Gutzwiller FS, Stallberg B. Economic burden of COPD in a Swedish cohort: the ARCTIC study. Int J Chron Obstruct Pulmon Dis. 2018;13:275-85

10. DiMatteo MR. Variations in patients' adherence to medical recommendations: a quantitative review of 50 years of research. Med Care. 2004:42(3):200-9.

11. Tashkin DP. Multiple dose regimens. Impact on compliance. Chest. 1995 107(5 Suppl):176S-82S.

12. Balkrishnan R, Christensen DB. Inhaled corticosteroid use and associated outcomes in elderly patients with moderate to severe chronic pulmonary disease. Clin Ther. 2000;22(4):452-69.

13. Yusuf S. Why do people not take life-saving medications? The case of statins. Lancet. 2016:388(10048):943-5.

14. Rand CS. Patient adherence with COPD therapy. Eur Respir Rev. 2005;14(96): 97-101.

15. Restrepo RD, Alvarez MT, Wittnebel LD, Sorenson H, Wettstein R, Vines DL, Sikkema-Ortiz J, Gardner DD, Wilkins RL. Medication adherence issues in patients treated for COPD. Int J Chron Obstruct Pulmon Dis. 2008;3(3):371-84.

16. George M. Adherence in asthma and COPD new strategies for an old problem. Respir Care. 2018;63(6):818-31.
17. Ari A. Patient education and adherence to aerosol therapy. Respir Care. 2015:60(6):941-55 discussion 955-947.

18. Toy EL, Beaulieu NU, McHale JM, Welland TR, Plauschinat CA, Swensen A, Duh MS. Treatment of COPD: relationships between daily dosing frequency, adherence, resource use, and costs. Respir Med. 2011;105(3):435-41.

19. Ramsey SD. Suboptimal medical therapy in COPD: exploring the causes and consequences. Chest. 2000;117(2 Suppl):33S-7S.

20. Vestbo J, Anderson JA, Calverley PM, Celli B, Ferguson GT, Jenkins C, Knobil K, Willits LR, Yates JC, Jones PW. Adherence to inhaled therapy, mortality and hospital admission in COPD. Thorax. 2009;64(11):939-43.

21. Khdour MR, Hawwa AF, Kidney JC, Smyth BM, McElnay JC. Potential risk factors for medication non-adherence in patients with chronic obstructive pulmonary disease (COPD). Eur J Clin Pharmacol. 2012;68(10):1365-73.

22. Antoniu SA. Adherence to inhaled therapy in COPD: effects on survival and exacerbations. Expert Rev Pharmacoecon Outcomes Res. 2010;10(2):115-7.

23. van Boven JF, Chavannes NH, van der Molen T, Rutten-van Molken MP, Postma MJ, Vegter S. Clinical and economic impact of non-adherence in COPD: a systematic review. Respir Med. 2014;108(1):103-13.

24. Vestbo J, Hurd SS, Agusti AG, Jones PW, Vogelmeier C, Anzueto A, Barnes PJ, Fabbri LM, Martinez FJ, Nishimura M, et al. Global strategy for the diagnosis, management, and prevention of chronic obstructive pulmonary disease: GOLD executive summary. Am J Respir Crit Care Med. 2013;187(4):347-65.

25. Raebel MA, Schmittdiel J, Karter AJ, Konieczny JL, Steiner JF. Standardizing terminology and definitions of medication adherence and persistence in research employing electronic databases. Med Care. 2013;51(8 Suppl 3):S11-21.

26. Bourbeau J, Bartlett SJ. Patient adherence in COPD. Thorax. 2008:63(9):831-8

27. Garcia-Aymerich J, Monso E, Marrades RM, Escarrabill J, Felez MA, Sunyer J, Anto JM, Investigators E. Risk factors for hospitalization for a chronic obstructive pulmonary disease exacerbation. EFRAM study. Am J Respir Crit Care Med. 2001;164(6):1002-7.

28. Cramer JA, Bradley-Kennedy C, Scalera A. Treatment persistence and compliance with medications for chronic obstructive pulmonary disease. Can Respir J. 2007:14(1):25-9.

29. Huetsch JC, Uman JE, Udris EM, Au DH. Predictors of adherence to inhaled medications among veterans with COPD. J Gen Intern Med. 2012;27(11): 1506-12.

30. Makela MJ, Backer V, Hedegaard M, Larsson K. Adherence to inhaled therapies, health outcomes and costs in patients with asthma and COPD. Respir Med. 2013;107(10):1481-90.

31. Vincken W, Dekhuijzen R, Barnes P. The ADMIT series — issues in inhalation therapy. 4 how to choose inhaler devices for the treatment of COPD. Prim Care Respiratory J. 2009;19(1):10-20.

32. Broeders ME, Sanchis J, Levy ML, Crompton GK, Dekhuijzen PR. The ADMIT series - issues in inhalation therapy. 2 improving technique and clinical effectiveness. Prim Care Respiratory J. 2009;18(2):76-82.

33. Han MK, Martinez CH, Au DH, Bourbeau J, Boyd CM, Branson R, Criner GJ, Kalhan R, Kallstrom TJ, King A, et al. Meeting the challenge of COPD care delivery in the USA: a multiprovider perspective. Lancet Respir Med. 2016; 4(6):473-526.

34. Moran C, Doyle F, Sulaiman I, Bennett K, Greene G, Molloy GJ, Reilly RB, Costello RW, Mellon L. The INCA(TM) (inhaler compliance assessment(TM)): a comparison with established measures of adherence. Psychol Health. 2017; 32(10):1266-87.

35. Trivedi $\mathrm{RB}, \mathrm{Bryson} \mathrm{CL}$, Udris $\mathrm{E}, \mathrm{Au} \mathrm{DH}$. The influence of informal caregivers on adherence in COPD patients. Ann behav med. 2012:44(1):66-72.

36. Sulaiman I, Cushen B, Greene G, Seheult J, Seow D, Rawat F, MacHale E, Mokoka M, Moran CN, Sartini Bhreathnach A, et al. Objective assessment of adherence to inhalers by patients with chronic obstructive pulmonary disease. Am J Respir Crit Care Med. 2017:195(10):1333-43.

37. Cushen B, Sulaiman I, Greene G, MacHale E, Mokoka M, Reilly RB, Bennett K, Doyle F, van Boven JFM, Costello RW: The clinical impact of different adherence behaviors in patients with severe chronic obstructive pulmonary disease. Am J Respir Crit Care Med 2018, 197(12):1630-1633. 